\title{
Patrimonialismo: o debate brasileiro e alguns elementos para sua crítica
}

\author{
Patrimonialism: the Brazilian debate and some \\ elements of critique
}

Ricardo Pagliuso Regatieri ${ }^{\star}$

\begin{abstract}
RESUMO
O presente artigo se dedica a reconstruir os principais momentos do debate sobre patrimonialismo no Brasil até os dias atuais e a pensar criticamente seus limites. Ele se inicia com o que chamo de discussão "clássica" sobre patrimonialismo no Brasil, que vai desde os ensaístas sociais da década de 1930 até discussões dos anos 1970 e começo dos 1980. Na sequência, trato de releituras sobre o tema do patrimonialismo que tiveram lugar nas últimas duas décadas. No próximo passo, mostro em que medida as críticas de Maria Sylvia de Carvalho Franco e Jessé Souza ao uso do conceito de patrimonialismo não conseguem transcender o terreno do debate em torno da "recepção equivocada" de Weber no Brasil. Em seguida, mostro como a leitura que Jessé Souza faz de Weber, influenciada pelas correntes das modernidades alternativas e modernidades múltiplas, impede que o autor brasileiro tenha uma visão mais alargada da modernidade que a veja como constituída de forma simultânea no centro e na periferia globais. Por fim, a partir do debate brasileiro sobre o patrimonialismo, esboço elementos de tal visão da modernidade.
\end{abstract}

Palavras-chave: Patrimonialismo; Weber; Brasil; Modernidade; Colonialidade

\footnotetext{
${ }^{*}$ Universidade Federal da Bahia, Salvador, BA, Brasil.

Professor Adjunto do Departamento de Sociologia e docente permanente do Programa de PósGraduação em Ciências Sociais da Universidade Federal da Bahia.

ricardo.pagliuso@ufba.br
} 


\begin{abstract}
This article aims to reconstruct the core moments in the debate on patrimonialism in Brazil up to the present day and present a critical reflection of the limits thereof. I begin by laying out what I refer to as the "classic" discussion of patrimonialism in Brazil, ranging from social essayists in the 1930s to academic discussions in the 1970s and early 1980s, followed by a review of debates which took place in the last two decades. I then show the extent to which Maria Sylvia de Carvalho Franco's and Jessé Souza's criticisms of the use of the concept of patrimonialism fail to go beyond the debate about the "erroneous interpretations" of Weber in Brazil. I go on to show how Jessé Souza's reading of Weber, influenced by the currents of alternative and multiple modernities, inhibits a broader view of modernity as concurrently constructed in both the global Center and Periphery. Finally, drawing on the Brazilian debate on patrimonialism, I sketch out the elements for such an approach to modernity.
\end{abstract}

Keywords: Patrimonialism; Weber; Brazil; Modernity; Coloniality

\title{
Introdução
}

Este artigo discute um tema que, em certa medida, funciona como um guia para mapear as ciências sociais brasileiras e, dentro delas, a sociologia em especial, no século 20 e neste início do século 21: o conceito weberiano de patrimonialismo e o embate em torno de sua adequação ou não para pensar a realidade social do Brasil. É possível dizer que a controvérsia sobre os elementos tradicionais e modernos presentes na formação e desenvolvimento da sociedade brasileira se deu, em larga medida, ao redor do conceito de patrimonialismo. Em sua sociologia da dominação, desenvolvida sobretudo em Economia e sociedade, Max Weber afirma que o patrimonialismo é um "caso especial da estrutura de dominação patriarcal” "que, por sua vez, é por ele tipificada como a forma mais pura de dominação tradicional. No patrimonialismo não existe delimitação entre os domínios público e privado, como acontece no caso da dominação legal, cujo tipo característico é a organização burocrática. A ordem patrimonial representa um equilíbrio tenso entre, por um lado, a tradição e, por outro, o arbítrio, as preferências pessoais e os caprichos

\footnotetext{
${ }^{1}$ Max Weber. Wirtschaft und Gesellschaft (1980), p. 583.
} 
do senhor. Em comparação com outra variante da dominação tradicional, o feudalismo, a dominação patrimonial confere maior espaço para a arbitrariedade, gerando maior instabilidade e um consequente "efeito inibidor para o capitalismo". ${ }^{2}$

Sugiro que o debate sobre patrimonialismo no Brasil opõe dois campos, com direito a uma terceira variante. Um deles enfatiza a herança ibérica e os traços patrimonialistas que estariam por trás de formas de conduta presentes na sociedade brasileira. O campo que se opõe diametralmente a esse sublinha o caráter desde sempre moderno da constituição de nossa sociedade, na medida em que ela esteve articulada ao capitalismo mercantil europeu. A terceira variante considera que, na verdade, tem lugar no Brasil uma mescla ou fusão de elementos da conduta patrimonialista senhorial e da conduta burguesa moderna. O presente artigo se dedica a reconstruir os principais momentos do debate sobre patrimonialismo no Brasil até os dias atuais e a pensar criticamente seus limites. Para fazê-lo, ele se inicia com o que chamo de discussão “clássica” sobre patrimonialismo no Brasil, que vai desde os ensaístas sociais da década de 1930 até discussões dos anos 1970 e começo dos 1980. Na sequência, trato de releituras sobre o tema do patrimonialismo que tiveram lugar nas últimas duas décadas. Com isso, passo de um exercício de caráter reconstrutivo para outro propriamente crítico, no qual reside o esforço central do texto. Trata-se de mostrar em que medida as críticas de Maria Sylvia de Carvalho Franco e Jessé Souza ao uso do conceito de patrimonialismo não conseguiram transcender o terreno do debate em torno da "recepção equivocada" de Weber no Brasil. No caso específico da leitura que Jessé Souza faz de Weber, influenciada pelas correntes das modernidades alternativas e modernidades múltiplas, aponto como ela impede que o autor brasileiro tenha uma visão mais alargada da modernidade, que a veja como constituída de forma simultânea no centro e na periferias globais. Um esboço de elementos de tal visão da modernidade, que permite colocar em xeque o binômio tradicional/ moderno forjado pela sociologia europeia e que segue até hoje sendo base para a maior parte da sociologia contemporânea, é apresentado na parte final do artigo, onde defendo que a crítica do patrimonialismo não pode prescindir da crítica da colonialidade.

${ }^{2}$ Max Weber. Wirtschaft und Gesellschaft (1980), p. 642. 


\section{A discussão "clássica" sobre herança ibérica e patrimonialismo no Brasil}

As obras fundadoras de Gilberto Freyre, Casa-grande \& senzala (1933), e de Sérgio Buarque de Holanda, Raízes do Brasil (1936), iniciaram debates que se prolongam até os dias atuais nas ciências sociais brasileiras. Para Gilberto Freyre, a Península Ibérica se constitui em um ponto de transição entre o Ocidente e o Oriente, ${ }^{3}$ e, em Casa-grande $\mathcal{E}$ senzala, uma ideia central é a que "diz respeito à ausência, tanto entre hispanos como, por herança, entre os brasileiros, de uma racionalidade tipicamente burguesa” (Bastos, 2001, p. 36). A "dupla gênese oriental/ocidental presente na Península Ibérica repete-se no Brasil respeitadas as características locais” (p. 35). A tese iberista de Freyre traz consigo a ideia de acomodação entre tradicional e moderno, interpretação que afasta a de dualidade, tema que serviu de eixo ao autor em estudos nos anos vinte (p. 38). Freyre destaca, em Casa-grande $\mathcal{E}$ senzala, a dimensão patriarcal da formação da sociedade brasileira, na qual as "grandes famílias proprietárias e autônomas" ou, melhor dizendo, os "senhores de engenho com altar e capelão dentro de casa e índios de arco e flecha ou negros armados de arcabuzes às suas ordens" (Freyre, 2003, p. 66), faziam a lei. Apontando para a "sobrevivência das velhas formas de organização do social”, as teses acerca do patriarcalismo desenvolvidas por Freyre frisam as bases oligárquicas familistas que vão conformar o poder estatal (Bastos, 2001, 39). ${ }^{4}$

Mas se Freyre vê continuidade entre os âmbitos da família e do Estado, buscando mostrar a plasticidade e as acomodações que permitiriam essa conjugação, Sérgio Buarque de Holanda tem a esse respeito uma posição distinta, ainda que seu diagnóstico se aproxime do de Freyre em muitos pontos, como é marcadamente o caso no que tange à ideia da herança ibérica. Para Sérgio Buarque, é significativa "a circunstância de termos recebido a herança [de formas de convívio, instituições e ideias] através de uma nação ibérica”, que faz parte de uma "zona fronteiriça”, sendo "um dos territórios-ponte pelos quais a Europa se comunica com os outros mundos" (Holanda, 1995, p. 31). Nessa porção da Europa, desenvolveu-se ao extremo

\footnotetext{
${ }^{3}$ Sobre esse tema, ver as discussões de Bastos (1998, 2001).

${ }^{4} \mathrm{O}$ "domínio privado estende-se em círculos concêntricos até atingir o público; não existe solução de continuidade entre o privado e o público; a família ao estender seu domínio substitui o Estado, não havendo diferenças de natureza entre um e outro” (Bastos, 2001, p. 40).
} 
uma "cultura da personalidade, que parece constituir o traço mais decisivo na evolução da gente hispânica, desde tempos imemoriais” (p. 32). A esse contexto da cultura da personalidade de raízes ibéricas, que prospera em solo brasileiro, pertence a figura do "'homem cordial”", cujo comportamento se funda antes na emoção do que nas regras impessoais da civilidade e no qual se pode ver de maneira "ativa e fecunda a influência ancestral dos padrões de convívio humano, informados no meio rural e patriarcal” ( $p$. 146-147). O patrimonialismo no âmbito do Estado seria uma manifestação do personalismo, na medida em que se tem como que uma passagem falhada do domínio particularista da família e das relações pessoais para o espaço impessoal da esfera pública. Diferentemente de Freyre, Sérgio Buarque vê "tensões entre as formas de sociabilidade que têm como eixo a família patriarcal e aquelas características do mundo moderno, que seriam a marca da cidade", e considera que, nesse processo falhado, tem lugar uma "transferência para o urbano da mentalidade e do modo de organização imperantes nos domínios rurais” (Bastos, 2005 p. 27-28). ${ }^{5}$

Pouco mais de duas décadas depois da obra de Sérgio Buarque, Raymundo Faoro publica Os donos do poder (1958), um marco fundamental das análises do fenômeno do patrimonialismo no Brasil. Assim como para Sérgio Buarque, em Faoro, a herança ibérica que finca raízes na nossa sociedade resiste a “todas as transformações fundamentais" (Faoro, 2008, p. 819). ${ }^{6}$ De acordo com Faoro, ela persiste mesmo no período pós-redemocratização. ${ }^{7}$ Ainda que “atuante debaixo de uma ordem nominalmente racional-burocrática” (Faoro, 1993, p. 16), o patrimonialismo brasileiro é imbuído de uma racionalidade pré-moderna $^{8}$ e é “intrinsecamente personalista, tendendo a desprezar a

\footnotetext{
${ }^{5}$ Buarque recorre à distinção de Weber entre o funcionário patrimonial e o burocrata, afirmando que, mesmo com a urbanização, no Brasil, "onde imperou, desde tempos remotos, o tipo primitivo da família patriarcal”, foi sempre difícil "aos detentores das posições públicas de responsabilidade, formados por tal ambiente, compreenderem a distinção fundamental entre os domínios do privado e do público” (Holanda, 1995, p. 145).

${ }^{6}$ Conforme Sérgio Buarque, de Portugal "nos veio a forma atual de nossa cultura; o resto foi matéria que se sujeitou mal ou bem a essa forma” (Holanda, 1995, p. 40).

${ }^{7}$ Em um texto de 1993, Faoro aponta para a continuidade do patrimonialismo "desde a monarquia patrimonial" da "dinastia de Avis (século XIV)" até os "planos financeiros das décadas de 80 e 90 deste século” (Faoro, 1993, p. 17; ver também: Faoro, 1992). Se Caio Prado Júnior considera que "não é preciso ir tão longe" para analisar as raízes da formação social brasileira, Faoro pensa exatamente o contrário e faz seu argumento remontar ao século XIV português.

${ }^{8}$ Conforme Luiz Werneck Vianna, para além de se inspirar em Weber, Faoro avizinha "o iberismo do despotismo oriental, retomando o argumento de Tavares Bastos e de Sarmiento - liberais ibero-americanos do século XIX” (Werneck Vianna, 1999, p. 175).
} 
distinção entre as esferas pública e privada” (Campante, 2003, p. 154). Para Faoro (1993, p. 154-155),

o particularismo e o poder pessoal reinam, o favoritismo é o meio por excelência de ascensão social, e o sistema jurídico, lato sensu, englobando o direito expresso e o direito aplicado, costuma exprimir e veicular o poder particular e o privilégio, em detrimento da universalidade e da igualdade formal-legal.

A herança ibérica, positivada por Freyre como elemento que possibilita a formação de uma nova civilização híbrida nos trópicos, ganha um sinal negativo em Sérgio Buarque e Faoro, já que, para esses últimos, ela colocaria obstáculos à racionalidade impessoal e abstrata.

Ainda que considere "cruciais as instituições e os padrões de relações sociais que foram trazidos de Portugal para o Brasil” (Portela Júnior, 2012, p. 18), em A revolução burguesa no Brasil (1975), Florestan Fernandes matiza o papel da herança ibérica no processo de desenvolvimento do capitalismo no Brasil. Durante o período colonial, a dominação patrimonialista se encontra dispersa pelo Brasil em domínios senhoriais relativamente autônomos entre si, transformando-se, depois, em "dominação estamental propriamente dita" (Fernandes, 2006, p. 61) com a centralização política levada a cabo pelo Estado nacional. No período mais recente, a burguesia nacional se associa com o capital internacional - o que caracteriza o capitalismo dependente. Mas nas fases moderna (1808-1860), competitiva (1860-1950) e monopolista (1950 até o presente) do capitalismo brasileiro, Florestan vê uma "impossibilidade de romper formalmente com o passado", o que impõe o "Estado-amálgama" (p. 90). Em sua análise da formação da ordem social competitiva no Brasil, o autor afirma que, em virtude de "suas raízes históricas, econômicas e políticas, ela prendeu o presente ao passado como se fosse uma cadeia de ferro", acorrentando "a expansão do capitalismo a um privatismo tosco, rigidamente particularista e fundamentalmente autocrático, como se o 'burguês moderno' renascesse das cinzas do ‘senhor antigo’” (p. 200).

Conforme Sedi Hirano, se Faoro vê a predominância de uma forma de capitalismo intimamente ligada à dominação patrimonial e ao poder pessoal, e se, para Florestan, elementos estamentais encontram-se em simbiose com princípios capitalistas, Maria Sylvia de Carvalho Franco defende que a sociedade brasileira se formou, desde o início da colonização, 
com base em determinações capitalistas (Hirano, 1988). Segundo Carvalho Franco, uma relação patrimonial típica, no sentido weberiano, nunca chegou a se constituir no país (Carvalho Franco, 1997). Não se pode falar em patrimonialismo no Brasil em razão da inexistência de uma tradição selando as relações de dependência pessoal ou o sistema do favor. ${ }^{9}$ No contexto brasileiro, prevaleceu a "arbitrariedade do mais forte: os vínculos pessoais nasceram do caráter mercantil da produção e a ela foram submetidos”, ou seja, o "interesse material submetia à sua razão os laços da estima e da afeição, atando-os ou destruindo-os” (Carvalho Franco, 1976, p. 62). Mas se críticas como as de Carvalho Franco tiveram lugar, a abordagem do patrimonialismo não perdeu força. Em seu livro de 1982, Bases do autoritarismo brasileiro, Simon Schwartzman defende, inspirado em Faoro, a tese do patrimonialismo. Schwartzman vê um permanente conflito entre um modelo de atividade política patrimonialista, patrocinado por oligarquias regionais e outro com um caráter de participação e que emana da sociedade civil (Schwartzman, 2007). Em entrevista concedida há alguns anos, o autor reafirma a importância do conceito de patrimonialismo para pensar o Brasil contemporâneo (Schwartzman, 2015).

\section{A discussão mais recente sobre patrimonialismo no Brasil}

Em um artigo e em um livro publicados em 2008, José Maurício Domingues argumenta no sentido de uma herança de características patrimonialistas no Brasil, as quais, no entanto, sofrem transformações decisivas (Domingues, 2008a; 2008b). Ele destaca três pontos: o patrimonialismo brasileiro contemporâneo não se restringe ao âmbito do Estado, mas está presente também na atuação dos agentes societários na vida cotidiana; ele não se legitima pela mera reprodução do passado, não correspondendo, desse modo, a uma forma de dominação tradicional, mas tem caráter moderno e modernizador; por fim, existiria uma lógica dual, de respeito a instituições impessoais, por um lado, e atitudes patrimonialistas e personalistas, que devem permanecer ocultas, por outro (Domingues, 2008b). Tal aposta

\footnotetext{
${ }^{9}$ Como argumenta Carvalho Franco em sua entrevista "As ideias estão no lugar", cujo título dialoga criticamente com o ensaio "As ideias fora do lugar", de Roberto Schwarz. Por sua vez, o texto de Schwarz repercute e reelabora as temáticas do "transplante" e do "desencaixe" presentes em Raízes do Brasil.
} 
em uma lógica dual - que caracteriza aquilo que se passou a chamar de neopatrimonialismo - é também compartilhada por Anthony Pereira em um artigo de 2016. Pereira condena a dilatação do conceito de patrimonialismo, que acabaria por explicar e justificar fenômenos díspares, sem precisálos, e por obscurecer "o caráter crescentemente racional-legal do Estado e o desenvolvimento do capitalismo no Brasil" (Pereira, 2016, p. 144). Defendendo que não é o caso de se abandonar o recurso à interpretação patrimonialista, o autor propõe “ver o 'patrimonialismo' como uma das diversas lógicas em operação no Estado brasileiro” (p. 148).

A partir de suas experiências na administração pública em diferentes níveis de governo (no plano federal, como Ministro da Educação, e no municipal, como Prefeito de São Paulo), Fernando Haddad afirma que Os donos do poder, de Faoro, "deveria ser relido, cum grano salis" (Haddad, 2017). Segundo Haddad, “[e]ntre nós, brasileiros, nenhuma obra do pensamento social e político descreve melhor o patrimonialismo, hoje com suas entranhas expostas no noticiário do país, do que Os donos do poder, de Raymundo Faoro". Haddad ressalta o fato de Faoro ter percebido que o patrimonialismo brasileiro, um tipo tradicional de dominação, se adapta à chegada do capitalismo, moldando-se e sobrevivendo à modernização. Retomando um artigo seu publicado anos antes, Haddad nomeia essa forma renovada de "patrimonialismo moderno".

Ao lado do legado da escravidão e da hierarquização racial dela resultante, bem como da desigualdade social e de gênero, em Sobre o autoritarismo brasileiro, Lilia Schwarcz aponta o personalismo, o mandonismo e o patrimonialismo como elementos que conformam o caráter autoritário da sociedade brasileira. Em seu capítulo sobre patrimonialismo, Schwarcz remete a Max Weber a discussão pioneira sobre tema, apresentando alguns autores brasileiros que se engajaram nessa discussão e argumentando que o patrimonialismo é uma espécie de constante que atravessa a sociedade brasileira desde a colonização até o período posterior à constituição de 1988. Assim, segundo a autora, boa parte das instituições brasileiras foi "desde os tempos coloniais (...) dominada por interesses de grupos de poder, que se apropriam de parte da máquina do Estado com fins particulares" (Schwarcz, 2019, p. 87). Para Schwarcz, na "breve história de cinco séculos [do Brasil], foi logo ficando patente a dificuldade que temos de construir modelos compartilhados de zelo pelo bem comum” (p. 64). A democratização e a 
modernização das relações sociais no país não teriam dado conta de "deter as práticas de patrimonialismo que se encontram bastante arraigadas e ajudam a explicar parte da crise que vivenciamos nos dias de hoje", de modo que, por aqui, "o patrimonialismo se mantém como um dos grandes inimigos da República” (p. 86-87).

Com base em uma leitura de Weber e em parte apropriando-se da abordagem de Carvalho Franco, Jessé Souza tem, nos últimos anos, desenvolvido uma crítica à tese do patrimonialismo. Na ausência de códigos tradicionais ou estamentais, tais como os existentes na Europa pré-moderna, a vida dos dominados no Brasil, por um lado, era pautada por uma constante imprevisibilidade e, por outro, dependia das preferências pessoais dos poderosos, o que forçava "os negativamente privilegiados a procurar agradar o senhor e sua família usando os recursos disponíveis a cada um” (Souza, 2000, p. 258). A partir da revolução modernizadora que Souza localiza no início do século dezenove com a vinda da corte portuguesa, o "vínculo de dominação passa a ser impessoal por referir-se a valores inscritos dentro da lógica de funcionamento das instituições fundamentais do mundo moderno, especialmente do mercado capitalista” (p. 261). As oposições baseadas em relações pessoais (senhor/escravo, coronel/dependente) passam a assumir formas impessoais (doutor/analfabeto, trabalhador qualificado/trabalhador não qualificado) assentadas nas dinâmicas da modernidade capitalista (p. 260). ${ }^{10}$

\section{A "recepção equivocada” de Weber no Brasil: as críticas de Maria Sylvia de Carvalho Franco e Jessé Souza ao uso do conceito de patrimonialismo}

Em seu texto "Weber e a interpretação do Brasil”, Werneck Vianna afirma que a mobilização de Weber por parte de analistas da sociedade brasileira se deu pela "perspectiva do atraso", à qual se associa um "diagnóstico que reivindica a ruptura" (Werneck Vianna, 1999, p. 174). Entretanto, na divisão que propõe entre aqueles que veem o patrimonialismo como um fenômeno alojado sobretudo no Estado e aqueles que consideram que

\footnotetext{
${ }^{10}$ A crítica de Souza que se encontra em A modernização seletiva (2000) foi desdobrada em obras posteriores que se dedicam à interpretação da sociedade brasileira, como Ralé brasileira (2009), Os batalhadores brasileiros (2010), A tolice da inteligência brasileira (2015), A elite do atraso (2017), Subcidadania brasileira (2018) e A classe média no espelho (2018).
} 
suas raízes são fundamentalmente societais, Werneck Vianna não faz jus à crítica à utilização do conceito de patrimonialismo levada a cabo por Maria Sylvia de Carvalho Franco. Se Raymundo Faoro e Simon Schwartzman são apresentados como representantes da primeira corrente, a segunda seria representada por Florestan Fernandes e Maria Sylvia de Carvalho Franco. Como apontado acima e como desenvolverei adiante, Carvalho Franco se opõe à mobilização do conceito weberiano de patrimonialismo na medida em que concebe as relações de dominação na sociedade brasileira como resultado do capitalismo moderno em sua roupagem periférica.

Tanto na crítica ao uso do conceito de patrimonialismo para tratar do Brasil levada a cabo por Maria Sylvia de Carvalho Franco na década de 1960 quanto na mais recente abordagem crítica desse conceito que tem sido desenvolvida desde o final da década de 1990 por Jessé Souza, a escravidão aparece como mediação explicativa fundamental para tratar da forma social que se desenvolve no país. Numa sociedade polarizada entre senhores e escravos, os homens livres, que não têm lugar nessa polaridade, estabelecem relações de dependência com os senhores. Aquilo que Carvalho Franco chama de "sistema do favor" é o conjunto de prestações e contraprestações que liga uns a outros. Assim, segundo ela, são as relações materiais de produção do sistema colonial que estão por trás de fenômenos como a ênfase nos vínculos pessoais, o mandonismo e o compadrio, e não uma herança ibérica de caráter tradicional que teria sido legada pela colonização portuguesa, como argumentam Gilberto Freyre, Sérgio Buarque de Holanda e Raymundo Faoro. Do mesmo modo que Carvalho Franco, Jessé Souza enfatiza o papel do sistema escravista na conformação das relações sociais - e raciais - brasileiras. A respeito da questão da herança ibérica, a posição de Souza aparece formulada em distintas obras suas como variações da ideia de que "[v]alores não se transportam como a roupa do corpo" (Souza, 2000, p. 252). Em consonância com Carvalho Franco, Souza afirma que não é possível falar de uma forma tradicional de dominação, como é o caso do patrimonialismo, numa sociedade cuja origem se assenta no sistema escravista, cuja base é mercantil.

Conforme Glaucia Villas Bôas, na altura da elaboração de Homens livres na ordem escravocrata, Maria Sylvia de Carvalho Franco estava "voltada para um alvo que não era simples e envolvia a recepção equivocada de Max Weber, segundo ela, em estudos que identificavam as sociedades subdesenvolvidas como sociedades tradicionais" (Villas Bôas, 2014, p. 19). Esses estudos, 
justamente, eram aqueles que vinham sendo desenvolvidos no âmbito de seu grupo intelectual na Universidade de São Paulo (Botelho, 2013). Como frisa André Botelho, a abordagem desenvolvida pela autora "remete a uma compreensão sociológica afinada à historicidade do processo social”, já que, "se a pessoalização das relações sociais e das práticas de poder não produz as mesmas sociedades que se formavam nas experiências históricas europeias, elas respondiam de modos próprios a determinações mais gerais da expansão do capitalismo e da construção da sociedade moderna" (2013, p. 354). Assim, a análise da formação social brasileira por Franco é marcada por "sua recusa em equacionar essa experiência em termos de patrimonialismo" (p. 350). Conforme a autora, os tipos ideais weberianos têm um caráter eminentemente histórico e visam expor o "caráter singular dos fenômenos culturais", de forma que a "negligência desses requisitos transforma-os em conceitos classificatórios que meramente sumarizam os traços comuns a certos fenômenos empíricos" (Carvalho Franco, 1997, p. 15-16). Nesse mesmo sentido, Reinhard Bendix, impulsionador da sociologia histórica e grande intérprete de Weber, havia escrito em um texto de 1963 que a análise sociológica comparativa revela que "muitos conceitos são generalizações disfarçadas [generalizations in disguise]" (Bendix, 1963, p. 533). ${ }^{11}$

Penso que Jessé Souza poderia também ser incluído na chave que Villas Bôas, referindo-se a Maria Sylvia de Carvalho Franco, nomeia de crítica à "recepção equivocada" de Weber. Referindo-se especificamente a Faoro, Souza escreve que, enquanto Weber usa o conceito de patrimonialismo de forma histórica e dinâmica, seu uso pelo autor brasileiro "é estático e tendencialmente a-histórico” (Souza, 2000, p. 171). Tratar-se-ia, continua Souza, de uma "transposição, para as situações históricas as mais variadas, de uma ideia que deixa, no limite, de ser uma categoria histórica e assume a forma de uma 'maldição', uma entidade demiúrgica que tudo explica e assimila” (p. 171). Tal crítica a Faoro se estende também a Buarque de Holanda em livro mais recente de Souza (2017, p. 193-194). Numa referência à discussão mais contemporânea, Souza afirma que "[f]alar de 'patrimonialismo moderno', como faz Haddad, é um contrassenso conceitual”, na medida em que, para Weber, “o patrimonialismo é inseparável de precondições que são

\footnotetext{
${ }^{11}$ André Botelho aponta o traço central que aproxima a abordagem dos dois autores: "tanto Bendix como Maria Sylvia de Carvalho Franco partem da valorização da perspectiva histórica que identificam e recuperam na sociologia de Max Weber para criticar os usos a-históricos que a sociologia da modernização e a sociologia do desenvolvimento estariam fazendo dos seus conceitos" (Botelho, 2013, p. 349).
} 
pré-modernas” (p. 189-190). Mas enquanto Buarque de Holanda, Faoro, bem como Simon Schwartzman, são objeto da crítica de Souza, o tratamento dado a Freyre é distinto. Souza vê duas grandes linhas-mestras do argumento de Freyre. Por um lado, Freyre positivaria a herança ibérica e sua abordagem do caráter português como o de um povo entre dois mundos (Ocidente e Oriente) que, justamente por essa condição, seria dotado de plasticidade e capacidade de misturar-se; tal visão forneceria as bases para a construção ideológica segundo a qual a escravidão no Brasil teve traços mais amenos do que em outras economias de plantation, tese que pouco depois desembocará na concepção de democracia racial. ${ }^{12}$ Mas, por outro, o tratamento dado por Freyre aos temas do sadomasoquismo e da ausência de limites à dominação dos senhores sobre os escravos ensejaria uma abordagem crítica que Souza busca desdobrar. Souza ressalta a discussão de Freyre a respeito da “escravidão muçulmana”, que permitiria

uma expansão e durabilidade da conquista inigualáveis, na medida em que associa o acesso a bens materiais e ideais muito concretos à identificação do dominado com os valores do opressor. A conquista pode, assim, abdicar da vigilância e do emprego sistemático da violência para a garantia do domínio e passar a contar crescentemente com um elemento volitivo internalizado e desejado pelo próprio oprimido (Souza, 2018a, p. 160).

O argumento que Souza já havia começado a desenvolver em $A$ modernização seletiva e continua a fazê-lo no recente Subcidadania brasileira é "que é precisamente a herança cultural moura, na forma da escravidão, que parece ter sido o elemento decisivo da singularidade da sociedade escravocrata colonial e, portanto, da semente da forma singular que a dependência pessoal assumiu entre nós” (p. 168).

Tanto Carvalho Franco quanto Souza frisam o equívoco da utilização do conceito de patrimonialismo, que para Weber funciona no âmbito da dominação tradicional, para tratar da sociedade brasileira, que nasce

\footnotetext{
12 “Como se sabe, Gilberto Freyre, em suas conferências apresentadas na Universidade do Estado de Indiana, no outono de 1944, isto é, entre setembro e dezembro, utilizou a expressão sinônima - "democracia étnica” - para se referir à catequese jesuíta: ‘[...] mas seu sistema excessivamente paternalista e mesmo autocrático de educar os índios se desenvolveu, por vezes, opondo-se às primeiras tendências esboçadas no Brasil que iam no sentido de una democracia étnica e social' (Freyre, 1947: 78). Na verdade, como veremos de imediato, a expressão de Freyre parece estar datada de novembro de 1943, quando se refere à tradição democrática da Bahia. A origem da ideia de democracia em Freyre, no entanto, já revelada por Elide Rugai Bastos (2001), remonta à crença no suposto caráter ibérico da civilização brasileira” (Guimarães, 2002, p. 306).
} 
como fruto da expansão mercantil europeia. Nesse sentido, a abordagem dos vínculos pessoais como derivados da lógica capitalista atuando no ambiente de pobreza material e desamparo dos agregados, levada a cabo por Carvalho Franco, não recorre, no curso de sua explicação, a nenhum tipo de herança tradicional. Souza, por sua vez, tem também procurado ressaltar a singularidade da formação social brasileira, na qual vínculos e valores são produzidos por relações sociais específicas geradas pelo sistema escravista e, posteriormente, pela modernização do país a partir do século 19, e não derivados de uma suposta herança ibérica tradicional. No entanto, sugiro que a adoção da tese freyreana da escravidão muçulmana por Souza cria um curto-circuito em seu argumento. E isso porque, se o autor argumenta fartamente acerca da impropriedade de se lançar mão de uma herança cultural tradicional, a ibérica, para dar conta de explicar um arranjo societário que não é o mesmo daquele de onde provém essa suposta herança, isto é, Portugal, não deveria também ser o caso de se recorrer a algo como uma herança cultural moura. Se, no embate em torno da herança ibérica, Souza assevera que '[v]alores não se transportam como a roupa do corpo', isso deveria, do mesmo modo, valer para uma suposta herança cultural muçulmana. As teses de Freyre sobre a forma moura de escravidão carregam para o fulcro da abordagem de Souza traços de um tipo de culturalismo que o autor tem se destacado em buscar refutar. Para além do imbróglio da questão das heranças culturais, a aposta numa herança cultural moura ou muçulmana reafirma, ao invés de colocar em xeque, a oposição binária Ocidente/Oriente.

Na interpretação de Souza, o problema da discussão brasileira sobre patrimonialismo - do mesmo modo que ele reputa aquela levada a cabo pela teoria da modernização a partir da sociologia de Talcott Parsons - reside não nas oposições feitas pelo próprio Weber entre tradicional e moderno e entre Ocidente e Oriente, mas sim numa leitura liberal e apologética de sua obra, que desconsidera sua crítica ao lado sombrio da racionalização ocidental. Em contraposição à primeira leitura, a segunda ofereceria elementos para a reflexão crítica sobre a sociedade capitalista e teria servido de base do assim chamado marxismo ocidental (Souza, 2016). Para Souza, o Weber crítico deve servir à elaboração de uma sociologia crítica contemporânea, para cuja construção Souza considera estar contribuindo. Jessé Souza é um grande conhecedor da obra de Max Weber, sobre a qual realizou doutorado na Universidade de Heidelberg, e é um de seus maiores intérpretes no Brasil. 
Ao criticar aquilo que, no curso das últimas duas décadas passou a chamar de 'sociologia da inautenticidade' ou 'sociologia do vira-lata' (Souza, 2015, 2017, 2018a, 2018b), Souza aponta como mal de origem dessas últimas a leitura e a mobilização de Weber por Buarque na elaboração de sua interpretação do Brasil. O que aparecia em tom mais analítico em $A$ modernização seletiva foi se convertendo, nos últimos livros de Souza, de tom marcadamente militante, em imprecações cada vez mais violentas contra Sérgio Buarque de Holanda, acusando-o, ao fim e ao cabo, de ser um ideólogo da elite paulista e estar por trás do projeto antinacional e privatista pelo qual ela se guia, representado pelo PSDB e posto em prática nos dois mandatos de Fernando Henrique Cardoso.

Algo, no entanto, parece faltar à apreciação do debate sobre patrimonialismo no Brasil, e esse aspecto também escapa a Jessé Souza. Dito de modo sucinto, esse elemento é a relação colonial de poder que está na base da formação das teorias dos autores clássicos da Sociologia, como Marx $^{13}$, Tönnies, Durkheim e, para a discussão que aqui me interessa, Weber. Se, no caso da crítica de Maria Sylvia de Carvalho Franco ao uso do conceito weberiano de patrimonialismo, a não tematização dessa dimensão ${ }^{14}$ poderia talvez ligar-se à pretensão "universalista” uspiana (Lynch, 2013, p. 754-758), no caso de Jessé Souza, escrevendo em um contexto teórico, histórico e político em que discussões sobre o caráter colonial e eurocêntrico do conhecimento das ciências humanas está sendo amplamente debatido, penso que é sua escolha teórica no que tange à interpretação da modernidade que o leva a passar ao largo de colocar em xeque pressupostos da construção weberiana. ${ }^{15}$. Com isso, sua crítica ao uso do conceito de patrimonialismo para interpretar a realidade brasileira fica incompleta.

\footnotetext{
${ }^{13}$ No caso de Marx, trabalhos mais recentes têm mostrado a evolução de seu pensamento no sentido de uma postura crescentemente crítica em relação ao colonialismo e ao eurocentrismo. Ver, por exemplo: Anderson, 2019; Tible, 2014.

${ }^{14}$ Em seu texto "Sobre o conceito de tradição", a autora não questiona o binarismo tradicional/ moderno tal como construído por Weber, mas sim seus usos pela sociologia do desenvolvimento. Partindo de uma reconstrução dos tipos ideais e de seu papel na metodologia de Weber, seu objetivo é antes chamar a atenção para “distorções" que teorias como a de Parsons e de Germani introduzem e que foram "muito difundidas na interpretação das sociedades 'atrasadas"” (Carvalho Franco, 1972, p. 39).

${ }^{15}$ De modo análogo a Carvalho Franco, que via distorção de Weber por parte da sociologia de matriz estrutural-funcionalista, Souza escreve que o "racismo culturalista [categoria na qual Souza enquadra Sérgio Buarque], na verdade, coloniza e distorce a leitura de Max Weber sobre a singularidade do Ocidente baseada na herança protestante ascética” (Souza, 2018a, p. 27). A pretensa singularidade do Ocidente, propriamente, nunca é posta em questão.
} 


\section{Weber via modernidades alternativas e modernidades múltiplas}

A partir da década de 1990, abordagens como a das modernidades alternativas e a das modernidades múltiplas passaram a ganhar terreno. O filósofo canadense Charles Taylor é um dos representantes da primeira corrente. A segunda tem como dois de seus representantes o sociólogo israelense Shmuel Eisenstadt e o sociólogo alemão Wolfgang Schluchter. Os três autores têm sido mobilizados por Jessé Souza nas duas últimas décadas na construção de sua abordagem sobre a sociedade brasileira e a questão do patrimonialismo. De Taylor, autor importante para a argumentação de Souza, interessa ao sociólogo brasileiro sua discussão da questão do reconhecimento (ou da ausência dele) e sua teoria acerca da construção da identidade moderna. Taylor é, por assim dizer, a contraparte canadense da corrente que busca desdobrar uma teoria do reconhecimento a partir de Hegel e que na Alemanha tem como representante maior o filósofo social Axel Honneth que, por sua vez, assina um elogioso posfácio a Subcidadania brasileira de Souza. De Eisenstadt e Schluchter, Souza mobiliza suas interpretações de Weber e dos diferentes caminhos para a modernidade. Vale notar, ainda, que Souza realizou seu doutorado, intitulado O desenvolvimento da modernidade ocidental, no Max-Weber-Institut für Soziologie da Universidade de Heidelberg sob a orientação de Schluchter, que é um dos maiores especialistas vivos na obra de Weber.

Em comum, ambas as correntes sustentam que a modernidade originalmente se desenvolve na Europa, a partir desse desenvolvimento original se propaga pelo mundo e, alcançando diferentes regiões e culturas, ganha distintas colorações. Num texto em que expõe de forma bastante concisa sua interpretação da modernidade, Taylor afirma que, do ponto de vista econômico (implantação de uma economia industrial de mercado) e institucional (burocratização do Estado e formas de governo), a "modernidade é como uma onda, um fluxo contínuo que engolfa uma cultura tradicional após a outra” (Taylor, 1999, p. 232). Entretanto, a "modernidade tal qual vivida desde dentro" envolve a capacidade de um povo de "encontrar recursos em sua cultura tradicional para adotar as novas práticas” (p. 233). Desse ponto de vista, "a modernidade não é uma onda única”, sendo "melhor falar de modernidades alternativas, na medida em que as culturas que emergem no 
mundo para levar adiante as mudanças institucionais se diferenciam umas das outras em aspectos importantes" (p. 233).

Eisenstadt e Schluchter, por sua vez, escrevem que sua "preocupação é lidar com os inícios da modernidade em uma perspectiva comparada" (Eisenstadt \& Schluchter, 1998, p. 1). ${ }^{16}$ Segundo os autores, ao invés de confinar a análise à Europa, como costumava ser o caso, eles pretendem tematizar se desenvolvimentos similares tiveram lugar em "outras civilizações e, em caso positivo, quando ocorreram”, bem como se foram "devidos principalmente à difusão ou a fatores endógenos [indigenous]" (p. 1-2). Os dois sociólogos sustentam que a "primeira, a assim chamada modernidade 'original', se desenvolveu na Europa e combinou várias dimensões estreitamente conectadas” (p. 3) - estruturais, institucionais e culturais. Para eles, o "primeiro programa cultural da modernidade" (p. 2) se originou na Europa, e também nos Estados Unidos, e posteriormente se espalhou pela América Latina, Ásia e África. Mas, diferentemente da teoria da modernização estrutural-funcionalista, que apostava numa convergência que levaria a um mundo moderno uniforme, ${ }^{17}$ a abordagem das modernidades múltiplas sustenta que "a expansão da modernidade

\footnotetext{
${ }^{16}$ O texto supracitado foi publicado na revista Daedalus, principal publicação de pesquisadores ligados à corrente das modernidades múltiplas, corrente da qual Eisenstadt foi talvez a figura mais importante até sua morte em 2010.

${ }^{17}$ O próprio Eisenstadt foi um destacado expoente da teoria da modernização de orientação estrutural-funcionalista. Tendo isso em vista, seria possível considerar a abordagem das modernidades múltiplas como uma tentativa de autocrítica da teoria da modernização, que, segundo Bhambra, não consegue, no entanto, efetivamente romper com essa última: “[a] literatura sobre modernidades múltiplas, de modo semelhante à da teoria da modernização de modo mais geral, identifica a modernidade com 'as importantes transformações das sociedades ocidentais durante os processos de industrialização, urbanização, e transformação política no final do século dezoito e início do século dezenove' (Wittrock, 1998, p. 19). Assim, a modernidade é compreendida simultaneamente em termos de suas constelações institucionais, isto é, sua tendência 'em direção a ordenamentos estruturais, institucionais e culturais universais' (Eisenstadt \& Schluchter, 1998, p. 3), e como um programa cultural 'assolado por antinomias e contradições internas, continuamente engendrando um discurso crítico e contestações políticas’ (Eisenstadt, 2000, p. 7). Entender a modernidade dessa maneira permite situar a modernidade europeia - vista sobretudo nos termos de uma combinação das formas institucionais e das formas culturais - como a modernidade original, e permite ao mesmo tempo visualizar diferentes codificações culturais que resultam em modernidades múltiplas. A ideia de modernidades múltiplas, portanto, é compatível com a ideia de um quadro comum de instituições modernas - por exemplo, a economia de mercado, o Estadonação moderno e a racionalidade burocrática - que se originou na Europa e subsequentemente foi exportado para o resto do mundo. Isso explica o aparente paradoxo que consiste em que Eisenstadt e Schluchter possam se dissociar do eurocentrismo ao mesmo tempo em que aparentemente aceitam seus pressupostos fundamentais, nomeadamente 'os pressupostos iluministas acerca da centralidade de um tipo eurocentrado de modernidade’ (1998, p. 5). $\mathrm{O}$ foco em diferentes trajetórias civilizacionais não europeias se baseia no pressuposto de que, ainda que essas trajetórias não tenham levado a uma modernidade original como na Europa, elas de todo modo conduziram à complexidade de padrões institucionais e de códigos culturais" (Bhambra, 2007, 65-66).
} 
para além da Europa tem que ser vista não como um processo de repetição, mas como a cristalização de novas civilizações, assemelhando-se de várias formas à expansão das grandes religiões e dos grandes impérios no período pré-moderno" (p. 2-3). Ou seja: "não foi a convergência, mas a divergência que governou a história da modernidade" (p. 5).

\section{A teoria social para além da Europa}

Sem deixar de considerar que a modernidade é um fenômeno eminentemente europeu, as correntes das modernidades alternativas e das modernidades múltiplas têm buscado compreender a pluralidade das expressões do moderno em diferentes partes do mundo. Entretanto, esse intento não se liberta, ao fim e ao cabo, do caráter eurocêntrico (ou centrado no Atlântico Norte) que marca a concepção de uma origem europeia da modernidade e sua posterior extensão mundo afora. Seguem estando aqui em jogo dois momentos distintos: (i) a produção da modernidade nos países centrais e (ii) sua subsequente difusão. Na América Latina, já Maria Sylvia de Carvalho Franco discutira, em seu debate com Roberto Schwarz e referindo-se de forma crítica à teoria da dependência (à qual associava Schwarz), as determinações recíprocas e a constituição simultânea, num mesmo movimento histórico, do centro e da periferia do sistema capitalista. Segundo a autora, “colônia e metrópole não recobrem modos de produção essencialmente diferentes, mas são situações particulares que se determinam no processo interno de diferenciação do sistema capitalista mundial, no movimento imanente de sua constituição e reprodução" (Carvalho Franco, 1976, p. 62). Como "desenvolvimentos particulares, partes do sistema capitalista”, ambas carregam, "em seu bojo, o conteúdo essencial - o lucro - que percorre todas as suas determinações”, de modo que "a produção e a circulação de ideias só podem ser concebidas como internacionalmente determinadas (...), sem a dissociação analítica de suas partes” (p. 62). Nessa argumentação dialética, fica clara a herança marxista da autora. Já para Souza, em consonância com Weber e com os proponentes das modernidades alternativas e múltiplas, o capitalismo moderno tem claramente origem no espaço norte-atlântico, podendo-se falar propriamente de modernidade no Brasil apenas após a chegada da corte portuguesa ao país em 1808, que acarreta a institucionalização de um 
mercado capitalista competitivo e de um Estado burocrático centralizado (Souza, 2000, 2015, 2017, 2018a, 2018b).

Ainda que tenha chegado às formulações acima, Carvalho Franco não chegou a levar adiante uma discussão sobre o caráter colonial e eurocêntrico do conhecimento das ciências humanas. Souza tampouco o faz, e, para ambos os autores, a discussão sobre os binarismos tradicional/moderno e Ocidente/Oriente fica no registro do lugar da sociedade brasileira nesses polos opostos e das interpretações equivocadas da sociologia de Weber levadas a cabo no Brasil. Entretanto, parece-me que uma discussão sobre a noção de patrimonialismo e a validade de seu uso para interpretar a formação social brasileira deveria ser capaz, na atualidade, de dar passos adiante, colocando em xeque não meramente o acerto ou o equívoco de leituras de Weber, mas o próprio caráter colonial da modernidade, da emergência da sociologia e dos binarismos com os quais a sociologia clássica trabalha e que continuam a informar uma parte importante da produção sociológica contemporânea.

Para o sociólogo peruano Aníbal Quijano (2000) e as sociólogas indianas Shalini Randeria (1999) e Gurminder Bhambra (2007), a modernidade não se constitui a partir de processos internos à Europa, conforme narrado pelos discursos filosófico e sociológico europeus de Kant a Habermas, Giddens, Eisenstadt e Taylor. Para além da fórmula da modernidade como resultante de três grandes rupturas, quais sejam, a Revolução Industrial no plano econômico, o Iluminismo no plano cultural e a Revolução Francesa no plano político (Sell, 2010), o colonialismo é uma dimensão central para a compreensão da ascensão do capitalismo moderno. Ou seja, o mundo moderno é resultado de processos que, a partir das grandes navegações, puseram em conexão a totalidade do mundo como um sistema, tendo a chegada dos europeus às Américas e sua conquista e colonização um papel fundamental. A discussão de Quijano sobre a colonialidade do poder é mais bem compreendida tendo-se em conta seu passado de teórico da dependência, sua releitura de Mariátegui e sua colaboração com Immanuel Wallerstein a partir de meados dos anos $1980 .{ }^{18}$ As formulações de Randeria

\footnotetext{
${ }^{18}$ Uma amostra dessa colaboração, que evidencia o diálogo e o entrelaçamento entre a abordagem da colonialidade de Quijano e a do sistema-mundo de Wallerstein, é seu texto conjunto sobre o papel das Américas para o desenvolvimento do moderno sistema mundial: Aníbal Quijano e Immanuel Wallerstein (1992): “La americanidad como concepto, o América en el moderno sistema mundial". Se a teoria do sistema-mundo é geralmente encarada como um desdobramento e uma atualização da teoria da dependência, sugiro que esse também é o caso da crítica da colonialidade.
} 
e Bhambra provêm de outra vertente, qual seja, a da abordagem das "histórias conectadas" ou "modernidades entrelaçadas". ${ }^{19}$

Apesar das distintas origens teóricas e geográficas, considero que, no que diz respeito aos três planos comumente considerados na discussão sobre a emergência da modernidade - econômico, cultural e político -, há convergências importantes entre os três autores: economicamente, o moderno mundo capitalista resulta da acumulação primitiva e da espoliação levadas a cabo nas colônias pelas metrópoles; politicamente, estabelece-se, desde o início, uma hierarquização racial com direitos distintos para brancos e não brancos e, enquanto paulatinamente prevalece o rule of law nas metrópoles, as colônias são lugares de um permanente estado de exceção; culturalmente, as colônias funcionaram como um espelho que permitiu definir a autoimagem da Europa, por meio dos discursos da literatura, da filosofia e, mais tarde, da sociologia, sendo a comparação com as populações colonizadas central para o surgimento da ideologia capitalista do progresso e da ideia da superioridade do mundo branco/europeu civilizado face aos povos atrasados das colônias. A modernidade capitalista se constitui, a um só tempo, nas metrópoles e nas colônias, não se propaga a partir da Europa engolfando diferentes regiões e culturas como argumentam as correntes das modernidades alternativas e a das modernidades múltiplas, ainda que a modernidade ganhe já em sua aurora uma face nas metrópoles e outra nas colônias, prolongando-se essa diferença na assimetria entre centro e periferia do hodierno sistema capitalista mundial - o conceito de colonialidade de Quijano justamente se diferencia do de colonialismo na medida em que identifica a reprodução de traços coloniais nas ex-colônias que se tornaram nações independentes.

Tendo em vista perspectivas como as de Quijano, Randeria e Bhambra, interessa sobretudo apontar para as limitações de críticas da utilização do conceito de patrimonialismo no Brasil que se baseiam na acusação de uma “recepção equivocada” da obra de Weber no país ${ }^{20}$. Ainda que se argumente

\footnotetext{
${ }^{19}$ Um dos marcos iniciais dessa escola indiana de análise histórica é o texto do historiador Sanjay Subrahmanyam. "Connected Histories: Notes towards a Reconfiguration of Early Modern Eurasia”.

20 Tocando na recepção e nos usos do conceito de patrimonialismo de Weber no Brasil, o artigo de Sell (2017) tem, na verdade, como foco central "mostrar a evolução do conceito de patrimonialismo na obra de Max Weber, com vistas a compreender as implicações dessa diferença (entre o modelo doméstico e o modelo institucional) na maneira em que ele foi recebido aqui [no Brasil]” (Sell, 2017, p. 332). Ainda que não pense nos termos de uma “recepção equivocada”, já que considera que "o processo por meio do qual as ideias circulam, a despeito de todas as transições e deslocamentos, não pode ser considerado ilegítimo” (p. 332), o texto de Sell se insere numa preocupação exegética de Weber.
} 
que Weber tinha uma visão contingente da mudança social, isto é, que esta tinha um caráter aberto e poderia trilhar diversos caminhos, e que, antes de conceitos propriamente ditos, os tipos ideais constituem exageros unilaterais de traços nunca encontráveis como tal na realidade e, portanto, meramente instrumentos heurísticos para avaliar a presença ou a ausência desses traços no universo pesquisado, ${ }^{21}$ o fato é que os tipos tradicional e racional-legal de dominação pressupõem o binômio tradicional/moderno. E a atribuição de um lado desse binômio - moderno - à Europa ou ao Atlântico Norte e de outro lado dele - tradicional - ao passado ou ao restante do mundo é um produto do caráter colonial e assimétrico da modernidade. Para Stuart Hall, o processo de produção de uma consciência europeia sobre si mesma desencadeado pela modernidade alcança a sociologia clássica e seus conceitos, que seguem reverberando a dicotomia entre o Ocidente e o "resto" do mundo (Hall, 1992).

Com efeito, como têm mostrado nas últimas décadas as críticas da colonialidade e pós-colonial, a emergência das ciências sociais europeias - e aqui pensando especificamente na sociologia weberiana - não pode ser desconectada do campo de tensões mais amplo que constituiu a Europa, e posteriormente ambos os lados do espaço norte-atlântico, como Ocidente, que passou a se entender como moderno. Nesse sentido, Quijano (2000, p. 208) chama a atenção para o fato de que o "capitalismo mundial foi, desde seu início, colonial/moderno e eurocentrado”. Portanto, a crítica do patrimonialismo não pode prescindir da crítica da colonialidade que, por sua vez, engloba questões como a escravidão, o extermínio dos indígenas, o caráter dependente das economias dos países da periferia capitalista e a reprodução do pensamento eurocêntrico nesses países. Se os grandes autores da sociologia nos ensinam a pensar e nos estimulam a ir além deles e produzir reflexões originais, eles não podem, por outro lado, ficar isentos de críticas no que tange a seus limites históricos. Isso de modo algum significa jogar fora o bebê com a água do banho. A partir do caso do debate brasileiro sobre patrimonialismo, argumentei neste artigo que é necessário levar discussões como a da existência ou não de traços tradicionais em nossa formação social ou da impropriedade da interpretação de Weber a outro patamar, que inclua a contextualização histórica da sociologia clássica - e da sociologia norte-

\footnotetext{
${ }^{21}$ É o caráter aberto e comparativo da obra de Weber e da corrente dela descendente das modernidades múltiplas que Sell (2015) busca frisar em seu texto "Max Weber e o problema do eurocentrismo".
} 
atlântica de um modo geral - no quadro do pensamento colonial moderno, o questionamento de seus limites e a busca por alternativas teóricas. Para tanto, é possível tirar proveito de perspectivas como as críticas da colonialidade e pós-colonial, em especial problematizando em que elas podem contribuir com análises sobre a sociedade brasileira e colocando-as em diálogo com intérpretes de nossa formação social.

\section{Referências}

Anderson, Kevin B. (2019). Marx nas margens: nacionalismo, etnias e sociedades não ocidentais. Boitempo.

Bastos, Élide R. (2005). Raízes do Brasil - Sobrados e mucambos: um diálogo. Perspectivas, 28, 19-36.

Bastos, Élide R. (2001). Brasil: um outro Ocidente? Gilberto Freyre e a formação da sociedade brasileira. Ciência \& Trópico, 29(1), 33-60.

Bastos, Élide R. (1998). Iberismo na obra de Gilberto Freyre. Revista USP, (38), 48-57. https://doi.org/10.11606/issn.2316-9036.v0i38p48-57

Bendix, Reinhard. (1963). Concepts and generalizations in comparative sociological studies. American Sociological Review, 28(4), 532-539. https://doi.org/10.2307/2090069

Bhambra, Gurminder K. (2007). Rethinking modernity: postcolonialism and the sociological imagination. Palgrave Macmillan.

Botelho, André. (2013). Teoria e história na sociologia brasileira: a crítica de Maria Sylvia de Carvalho Franco. Lua Nova, (90), 331-366. https://doi. org/10.1590/S0102-64452013000300012

Campante, Rubens G. (2003). O patrimonialismo em Faoro e Weber e a sociologia brasileira. Dados - Revista de Ciências Sociais, 46(1), 153193. https://doi.org/10.1590/S0011-52582003000100005

Carvalho Franco, Maria S. (1997). Homens livres na ordem escravocrata. Editora da Unesp.

Carvalho Franco, Maria S. (1976). As ideias estão no lugar. Cadernos de Debate, 1, 61-64.

Carvalho Franco, Maria S. (1972). Sobre o conceito de tradição. Cadernos Centro de Estudos Rurais e Urbanos, 5, 9-40. 
Domingues, José M. (2008a). Latin America and contemporary modernity: a sociological interpretation. Routledge.

Domingues, José M. (2008b). Patrimonialismo e neopatrimonialismo. In L. Avritzer et al. (Org.), Corrupção: ensaios e críticas (pp. 158-162). Editora UFMG.

Eisenstadt, Shmuel N., \& Schluchter, Wolfgang. (1998). Introduction: Paths to early modernities - a comparative view. Daedalus, 127(3), 1-18.

Faoro, Raymundo. (2008). Os donos do poder. Formação do patronato político brasileiro. Globo.

Faoro, Raymundo. (1993). A aventura liberal numa ordem patrimonialista. Revista USP, (17), 14-29. https://doi.org/10.11606/issn.2316-9036. v0i17p14-29

Faoro, Raymundo. (1992). A questão nacional: a modernização. Estudos Avançados, 6(14), 7-22. http://dx.doi.org/10.1590/S0103$\underline{40141992000100002}$

Fernandes, Florestan. (2006). A revolução burguesa no Brasil: ensaio de interpretação sociológica. Globo.

Freyre, Gilberto. (2003). Casa-grande \& senzala: formação da família brasileira sob o regime da economia patriarcal. Global.

Guimarães, Antonio S. A. (2002). Democracia racial: el ideal, el pacto y el mito. Estudios Sociológicos, 20(2), p. 305-333.

Haddad, Fernando. (2017). Vivi na pele o que aprendi nos livros: um encontro com o patrimonialismo brasileiro. Piauí, 129. Disponível em: https:// piaui.folha.uol.com.br/materia/vivi-na-pele-o-que-aprendi-nos-livros/

Hall, Stuart. (1992). The West and the rest: discourse and power. In S. Hall \& B. Gieben (Ed.), Formations of modernity (pp. 185-227). Cambridge: Open University Press.

Hirano, Sedi. (1988). Pré-capitalismo e capitalismo. Hucitec.

Holanda, Sérgio B. (1995). Raízes do Brasil. Companhia das Letras.

Lynch, Christian E. C. (2013). Por que pensamento e não teoria? A imaginação político-social brasileira e o fantasma da condição periférica (18801970). Dados - Revista de Ciências Sociais, 56(4), 727-767. https://doi. org/10.1590/S0011-52582013000400001

Pereira, Anthony W. (2016). Is the Brazilian State "patrimonial”?. Latin American Perspectives, 43(2), 135-152. $\underline{\text { https://doi. }}$ org/10.1177\%2F0094582X15616119 
Portela Júnior, Aristeu. (2012). Florestan Fernandes e o conceito de patrimonialismo na compreensão do Brasil. Plural - Revista do Programa de Pós-Graduação em Sociologia da USP, 19(2), 9-27. http:// dx.doi.org/10.11606/issn.2176-8099.pcso.2012.74433

Prado Júnior, Caio. (1996). Formação do Brasil contemporâneo: colônia. Brasiliense.

Quijano, Aníbal. (2000) Colonialidad del poder, eurocentrismo y América Latina. In E. Lander (Comp.), La colonialidad del saber: eurocentrismo y ciencias sociales: perspectivas latinoamericanas (pp. 117-142). CLACSO.

Quijano, Aníbal, \& Wallerstein, Immanuel. (1992). La americanidad como concepto, o América en el moderno sistema mundial. Revista Internacional de Ciencias Sociales, 134, 583-591.

Randeria, Shalini. (1999). Jenseits von Soziologie und soziokultureller Anthropologie: zur Ortbestimmung der nichtwestlichen Welt in einer zukünftigen Sozialtheorie. Soziale Welt, 50(4), 373-382.

Schwarcz, Lilia M. (2019). Sobre o autoritarismo brasileiro. São Paulo: Companhia das Letras.

Schwarz, Roberto. (2005). As ideias fora do lugar. In R. Schwarz, Cultura e Política. Paz e Terra.

Schwartzman, Simon. (2015). Livros de Simon Schwartzman radiografam o Brasil contemporâneo. Entrevista com Simon Schwartzman. Jornal da UNICAMP, 622, 6-7.

Schwartzman, Simon. (2007). Bases do autoritarismo brasileiro. Publit.

Sell, Carlos E. (2017) The two concepts of patrimonialism in Max Weber: from the domestic model to the organizational model. Sociologia $\mathcal{F}$ Antropologia, 7(2), 315-340. https://doi.org/10.1590/2238-38752016v721

Sell, Carlos E. (2015, 20-23 jul.) Max Weber e o problema do eurocentrismo [Apresentação de trabalho]. XVII Congresso Brasileiro de Sociologia, Porto Alegre.

Sell, Carlos E. (2010). Sociologia clássica: Marx, Durkheim e Weber. Vozes.

Souza, Jessé. (2000). A modernização seletiva: uma reinterpretação do dilema brasileiro. UnB.

Souza, Jessé. (2018a). Subcidadania brasileira: para entender o país para além do jeitinho brasileiro. Leya. 
Souza, Jessé. (2018b). A classe média no espelho. Estação Brasil.

Souza, Jessé. (2017). A elite do atraso: da escravidão à Lava jato. Leya.

Souza, Jessé. (2016). Max Weber y la orientalización de América Latina. In Á. Laiz \& E. Weisz (Ed.), Max Weber en Iberoamérica: nuevas interpretaciones, estudios empíricos y recepción. Fondo de Cultura Económica.

Souza, Jessé. (2015). A tolice da inteligência brasileira: ou como o país se deixa manipular pela elite. LeYa.

Subrahmanyam, Sanjay. (1997). Connected histories: notes towards a reconfiguration of early modern Eurasia. Modern Asian Studies, 31(3), p. 735-762. https://doi.org/10.1017/S0026749X00017133

Taylor, Charles. (1999). Nationalism and modernity. In R. Beiner (Ed.), Theorizing nationalism. State University of New York Press.

Tible, Jean. (2014). Marx e os outros. Lua Nova, (91), 199-228. https://doi. org/10.1590/S0102-64452014000100008

Villas Bôas, Glaucia. (2014). A recepção controversa de Max Weber no Brasil (1940-1980). Dados - Revista de Ciências Sociais, 57(1), 5-33. https:// doi.org/10.1590/S0011-52582014000100001

Wallerstein, Immanuel. (2004). World-systems analysis: an introduction. Duke University Press.

Wallerstein, Immanuel. (1976). Semi-Peripheral Countries and the Contemporary World Crisis. Theory and Society, 3(4), 461-483. https:// doi.org/10.1007/BF00161293

Weber, Max. (1980). Wirtschaft und Gesellschaft. Grundriß der verstehenden Soziologie. Mohr.

Werneck Vianna, Luiz. (1999). Weber e a interpretação do Brasil. In J. Souza (Org.), O malandro e o protestante: a tese weberiana e a singularidade cultural brasileira (pp. 173-194). Editora da Universidade de Brasília.

Wittrock, Bjorn. (1998). Early Modernities: Varieties and Transitions. Daedalus, 127(3), 19-40.

\section{(cc) $\mathrm{EY}$}

Licenciado sob uma Licença Creative Commons Attribution 4.0 